\title{
Assessing Quality Performance of Engineering Projects: A Case of The Ghana Armed Forces (GAF)
}

\author{
Prince Kelvin Owusu ${ }^{1} \&$ Atsu Agbenyega ${ }^{2}$ \\ ${ }^{I}$ Information Systems Department, Ghana Communication Technology University, Ghana. \\ ${ }^{2}$ Training Department, Kofi Annan International Peacekeeping Training Center, Ghana.
}

DOI: $10.46382 / M J B A S .2020 .4306$

The term Total quality management (TQM) refers to a structured approach to the complete management of an organization for the continuous improvement of the quality of its outputs. The process focuses mainly on the customer or the end user. The main objective of this study was to assess the quality performance of engineering projects of the GAF with emphasis on projects undertaken by the Ghana Army Corps of Engineers. The specific objectives were; to assess engineering projects of the $G A F$, examine the quality performance of GAF projects particularly those undertaken by the Ghana Army Corps of Engineers and finally ascertain the challenges to the quality of GAF projects undertaken by the Ghana Army Corps of Engineers. Data was collected through questionnaire and interviews. Out of 35 questionnaires distributed, 30 were retrieved. 3 interviews were also conducted with some officials of the GAF. The GAF as an institution has undertaken numerous construction projects over the years. The projects are mainly designated either as horizontal or vertical constructions projects. The horizontal projects are those lying on the land, floor or ground and include road projects, bridges and airfield construction and repairs, among others. Vertical construction projects on the other hand comprise of projects that have elevations or heights. They include the constructions of school buildings, military accommodations and all others that have height. From the data gathered from the field, TQM is a philosophy that is well understood by personnel of the GAF. The statistics show that, a whopping 26 respondents (87\%) out of the 30 know about the term, Total Quality Management (TQM). The data gathered and scrutinized also showed that, 25 respondents (83\%) believed the GAF put the customer (the beneficiary) at the center of its plan in all engineering projects undertaken by Ghana Army Corps of Engineers. 16 of the respondents said TQM is successfully employed by the GAF in its engineering projects. This research concluded that, although the GAF has successfully undertaken numerous horizontal and vertical construction projects, it is not all that meet the required standard of quality. The research also identified bureaucracy and poor measurement strategies as major challenges to the implementation of TQM in GAF engineering projects. In view of the aforementioned, it was recommended that, there should be continuous education or retraining of the GAF staff on TQM. The bureaucracy and long chain of command within the GAF should also be revised to ensure efficient and timely decision making on projects to reduce delays and also improve performance.

Keywords: Quality performance, Total quality, Engineering project, Ghana armed forces, Quality management.

\section{Introduction}

Shelter undoubtedly is one of the most important necessities of human existence. According to Maslow's theory of needs, shelter is one of the basic requirements of life. It is one of the first steps of internal motivation. In line with this theory and other conditions, construction in all forms evolved over the years for the provision of shelter and the survival on man. In all construction project however, quality is key and must be certified in other to ensure the sustainability of the project. "Quality" is a word derived from the Latin word "Qualitas" which means the essence of the thing, person or the degree of goodness. Quality is conformance to requirements and specifications and what is pleasing to the customer. Quality is the overall product attribute and characteristics that satisfy the customer's needs and expectations. It is therefore the hallmark of all projects and must be ensured throughout the project's life cycle. The importance of Quality Management in any construction project cannot be overlooked. This is because, the sector constitutes the largest in any nations development and economic prospect (Farooqui, Masood and Aziz, 2008). The construction sector is considered as the basic industry on which a country's development hinges. In broader terms, a nation's development is measured by the quality of its infrastructure and by extension, its construction projects (Wasiu, Aliyu and Modupe, 2012).

The Ghana Armed Forces (GAF) like most Armed Forces the world over, has Engineering Units that undertake construction or provide engineer effort for operational needs and to a large extent, the needs of the country. Vivid 
examples are the works of the United States Army Corps of Engineers, the Corps of Royal Engineers of the United Kingdom (UK) and the South African Army Engineer Corps (ISSUP Bulletin, 5/2009). All these Engineer formations provide combat engineer efforts during combat and civil engineering capabilities in peace time usually in-home countries. Since the establishment of the GAF, the Army Corps of Engineers has undertaken numerous engineering projects locally and internationally. These projects range from construction and rehabilitation of roads, dams, airfield, bridges as well as construction and renovation of building infrastructure among others.

Notable construction projects undertaken by the GAF Corps of Engineers are the construction of feeder roads in the Afram Plains District of the Eastern Region and Sefwi Wiawso in the Western Region of Ghana. The Corps has also undertaken various projects across the country in support of national development (MoD, 2012). All these are in line with the tenets of the 1992 Constitution of the Republic of Ghana (Art 201 (3)).

Earlier studies have focused significantly on the effectiveness of the GAF and the role of women in peacekeeping. Recent studies have systematically demonstrated how peacekeeping operations have benefited Ghana in consolidating its peace and security. Within this newer researches, there is a growing focus on how the different components of the GAF contribute to the development of the Armed Forces itself and the country as a whole as captured in Festus Aubyn, Kwesi Aning, Emma Birikorang, Fiifi Edu-Afful, Maya Mynster Christensen \& Peter Albrecht (2019). One area that has not been assessed is the quality of engineering projects undertaken by the GAF. There is also a general lack of public awareness about engineering projects undertaken by GAF and little scholarly attention has be given to analyzing the quality performance of most of these engineering projects. This lack of awareness about the quality of engineering projects undertaken by the GAF has inspired this study to assess the quality performance of engineering projects of the GAF, with particular emphasis on construction projects undertaken by the Ghana Army Corps of Engineers. The roles played by the GAF in protecting the territorial integrity of Ghana and international peacekeeping operations have been widely acclaimed with lots of benefits. The country has benefited politically, socially and economically.

Aside all these, there is still much to unearthed about the capabilities and contributions of the GAF. Also, several studies have been conducted in recent times such as Aubyn and Kwesi (2015), Aboagye and Atintande (2012) with regards to how the role and mandate of the GAF has impacted on the security of Ghana and the international community in general. However, there is a dearth of scholarly exploration, as well as public awareness on the expertise such as engineering works undertaken by the GAF and its quality performance standards. This study therefore tries to provide answers to the following questions: What are some of the engineering projects undertaken by the GAF? How has Quality performance help in achieving quality in engineering projects undertaken by the Ghana Army Corps of Engineers? What are the challenges to effective implementation of quality in GAF projects undertaken by the Ghana Army Corps of Engineers? The study also assessed the quality performance of engineering projects undertaken by the Ghana Army Corps of Engineers to further promote the good image of the GAF.

This gap in literature is what this study sought to fill by assessing the quality performance of engineering projects of the GAF, with specific reference to the Ghana Army Corps of Engineers. 


\section{Literature Review}

\section{A. Quality Defined}

The definition of quality cannot be overemphasized or underestimated. Though many scholars have made attempts to clearly outline the meaning of the term, it was realised that they rather stated some ingredients or dimensions that needed to be present to constitute 'quality' as a word. According to Raja and Mubeena (2017), quality comprises when it comes to competitive sense a diploma of excellence and this includes features such as reliability, serviceability, maintainability, or even personal features. They further opined that, these are even depended on the modus operandi and the cost of the whole process. In order words, it is considered that the entire quality process or product must meet a certain level of fitness test or degree of characteristics to classify it as of quality (Sepalla, 2015). Khodeir (2015) postulated that, quality has a commencement stage and it begins with the commitment of the client. Quality eventually must start with total commitment from the initial stage and all other features must be present in continuation, in the end and even at the maintenance stage when the product or process is completed and put to use.

\section{B. Quality Management Defined}

Management is considered as a process of making things or productive blueprints come to being through the process of planning, organising, directing, measuring, overseeing and controlling in an environment or a confined space. In an event where management wants to deal with quality or standards or is dealing with certain features to be met in their correct sense and order, the process through which it occurs is known as Quality Management (Wei, Skibniewski \& Balali, 2016). Gogate, Mukhopadhyaya, Mahadik, Naduvilath, Sane, Shinde and Holden (2013) stated that, quality management is a managerial approach that is used broadly in maintaining and improving quality standards in order to achieve customer satisfaction. Warsame, Borg and Lind (2013) stated that, quality management is to achieve high level of quality for a project. The focus according to him is the identification of factors that affect quality management in infrastructure projects.

\section{Total Quality Management}

Total Quality Management refers to a form of quality improvements practices, methodologies and so forth that is focused mainly on service delivery and customer satisfaction. The Total Quality Management practitioner must understand what the customer desires in terms of standards and quality first before planning, designing, production and delivery. Total Quality Management was first instituted in Japan by Toyota and later spread rapidly across the world (Alomi, Alghamdi \& Alattyh, 2015; Finkler, Smith \& Calabrese, 2018)

\section{Crosby's Theory}

Philip Crosby developed a four-point based approach known as the absolutes of quality management similar to Deming's fourteen points. According to Crosby in 1964, if you spend money on quality, it is money that is well spent. His basis is on four absolutes of quality management; defining quality as adherence to requirements, 
preventive measure is the best way to ensure quality, errors are the performance standards for quality and quality is measured by the price of nonconformity (Boughzala, 2014).

\section{E. Quality Management in Construction Industries in Africa}

There has been a plethora of studies in Africa that cover quality management with different findings in construction and or engineering. That notwithstanding, the outcomes of those research have imports in quality management of the GAF and its engineering projects. Mporanzi and Mulyungi (2018) undertook a research on the topic, 'Effect of Quality Management on Sustainability of Construction Projects in Rwanda: A Survey of Selected One Hundred First Category Public Buildings in City of Kigali.' The research concluded that, there was a weak legal foundation between public building projects and their construction and sustainability. The researchers also realised that there was a dissimilar connection between public building codes or standards and their sustainability. Additionally, it was identified that, there a problem between project management methodologies and sustaining public buildings. All the above findings demonstrated; Rwanda has a great challenge with quality management of its public facilities. According to Badu, De-Graft, Edwards and Holt (2011) in a research entitled, 'Innovative financing of infrastructure projects in Ghana: conceptual and empirical observations'; governments of third-world countries are still depended on private hands to fund projects, there is little willingness of government to direct funds towards infrastructure projects, governments have limited funds and banks has also limited investment into infrastructural projects, accessing private funds has also been difficult because of world economic downturn phobia, among others. Hence, the results of this research from Ghana are not also a good note for Africa. There is still room for improvement.

Another study done by Mohammed, Ibrahim and Khodeir (2013) on application of total quality management in construction projects in Egypt came out clear that the construction firms still have setbacks. Their issues included low productivity, health and safety problems, bad working conditions and inferior quality. Meanwhile, the main canker in Egypt has to do with a hindrance to utilize total quality management in the construction industry. Eventually, the studies carried out though not all have been tackled, these examples from East, West and North Africa indicated that we have many hurdles to overcome when it comes to quality management.

\section{F. Quality Management in Construction Projects by the Military}

Some scholarly works have been undertaken in recent times on the contributions of the GAF to national and international peace and security as well as development. However, these works have ignored the impact of GAF with regards to quality performance in its engineering projects. It is in this vein, that some of these works will be reviewed to indicate how they contribute significantly to the topic under study as well as identify gaps which this study will attempt to fill. All engineering projects has codes and conducts to which all outfits or the process of coming out with artefacts must comply. For instance, the Air Force Instruction (AFI) of America contains the scope defining the types of facilities to which all military designs must take, applicability explaining all criteria that should be observed, restrictions and deviations allowed or not, design agents or agents that should design military artefacts, who is to develop construction policies or programs, the civil engineer who is to initiate 
the construction policies or programs, all construction requirements and management procedures, where the project should be sited, antiterrorism standards being adhered to, model building code, cost management procedures, value engineering to analyze and improve designs, respecting the environmental standards, responsibilities of all individuals involved in the process of construction and how the project is funded continuously (Air Force Instruction, 2015).

\section{G. Challenges in Quality Management in Construction Industries}

\section{Time Constraints}

Fairly all projects have timelines and deadlines. There could be wide range of time from the commencement, continuation, completion and up to the time the project is handed over to the country or owner or international body. In a circumstance where the time available is limited, especially political projects as of the case of Ghana, management with all the supervisory skills must hasten though it may go down against a quality product or process. The management must then put their entire arsenal on board to ensure they meet the deadline (Garcia, Cumo, Pennacchia, Pennucci, Piras, De Notti \& Roversi, 2017).

\section{Training}

Training is an essential component of ensuring that standards of projects are met. There are pre- training, on-the-job training and perhaps retraining. Most of the challenges appear to come from on-the-job training and retraining. The issues are while projects are being undertaken, management have to expend another time tutoring how effective practices should be done to ensure that all quality features are adhered to. The other is noticing that there is gross decline in capacity of employees or being handed a new project where labour need to be reskilled to meet job challenges (Bora \& Alamsyah 2018). Weather management may have an upper hand over conducting feasibility studies, changing plans on the drawing board and every other thing on the architecture of say an engineering project, but one thing which no one can predict and it is out of control is weather or climatic changes. Though predictable via giving attention to meteorological updates, it sometimes gets mad at all reports. Flooding, typhoon could occur and may distort projects (Zhu, \& Pasadilla, 2016). No project occurs in a vacuum. There could be a forest to be cleared, a building to be demolished or bridge to construct over a water body. All these go a long way to affect the plan or the outcome of the project (Bora \& Alamsyah 2018).

\section{Research Methodology}

Methodology refers to how the researcher goes about practically finding out whatever is believed can be known. Selection of a study methodology is not dependent on the type of paradigm adopted but rather on the objectives set to be achieved by the researcher (Noor, 2012). The study relied on the mixed method approach for data collection and analysis. The technique is a research methodology in which a researcher collects and analyses both quantitative and qualitative data within the same study. It was used through the administration of questionnaires and the conduct of in-depth interviews with selected respondents. The method ensures the acquisition of both "objective data" and the "human element" or perspective required for better analysis. Qualitative research involves the adoption of research methods for collection and analysis of non-numeric data. According to Myers (2013) 
qualitative research involves designed sets of techniques to enable researchers obtain understanding of the immediate social-cultural surroundings within which people live. The goal of qualitative research is to attain an insider's view of the group under study. Qualitative research produces general understandings of rich, contextual, and generally unstructured, non-numeric data through conversations with research participants in a natural setting (Rovai et al, 2013). This research employed the interpretivists, exploratory and descriptive research designs. Ponelis (2015) posited that, qualitative approach preferably gives valued results required for interpretivists to fully comprehend contexts. In a similar context, Zanial (2007) also asserts that, qualitative methods are reinforced by Interpretivists because the paradigm "portrays a world in which reality is socially constructed. Quantitative research on the other hand, involves the analysis and use of numerical data using statistical techniques. The method is designed to yield reliable statistical data that communicates how people think about something or do things. Generally, quantitative research is suitable for large scale needs assessment and it is autonomous of the researcher. The quantitative data is typically in numerical form with results expressed in ratios or ranges or even as averages. Exploratory design often relies on secondary research such as reviewing available literature or data and conducting in-depth interviews, case studies and pilot studies (Dellinger and Leech, 2007). This study employed the exploratory qualitative research design with the administration of some questionnaires with responses to clarify ambiguous variables (i.e. on quality and engineering projects) of the objectives of the study. The exploratory and descriptive designs helped in providing additional information where limited information existed and helped to identify gaps in existing literature.

Exploratory design was employed due to the flexibility or its non-rigid nature. The method involves exploring suitable avenues of obtaining data without any strict restrictions and applications. This design helps in formulating a more precise problem statement and developing a good hypothesis, (Shields and Rangarjan, 2013). The exploratory design also helped in investigating social phenomenon without explicit expectations, (Shields and Rangarjan, 2013). This is because, the design helped in making holistic investigation and analysis about data obtained from sources indicated earlier without any prejudices or personal sentimentality. The descriptive design was used to establish facts and relationships by describing into detail, the quality performance of the engineering projects carried out by Ghana Armed Forces (GAF).

Data collection is one of the most important aspects of any research studies. Ritchie et al (2013) explain that, research can be conducted with different methods, but every research is based on the data which is analyzed and further clarify to get information. There are two main methods of data collection. These are primary data and secondary data. Basically, the primary data use the survey, experiments, interviews and direct observation whilst the secondary data may be obtained from many sources including literature, newspaper, books, magazines, industry surveys as well as journal articles. This particular study used to both the primary and secondary sources of data in assessing quality performance in engineering projects of the Ghana Armed Forces (GAF).

Data are information gathered and collected based on the research purpose. Primary data is conducted from the first-hand sources which have not been published yet and the data is more reliable, accurate and objective (Pienta et al., 2010). There are few methods used in collecting primary data which includes interviews, observation and 
questionnaire. In this study, primary data was obtained through unstructured expert interviews with workers, officials and personnel of the Ghana Armed Forces, particularly those of the Ghana Army Engineer Corps. In addition, public pronouncements of military personnel and security experts pertinent to the topic was also considered. The secondary data refers to existing data that has been obtained from other researchers and has been published previously (Silverman, 2016). Normally, the secondary data is simpler and easier to be collected as it can be obtained from various ways such as through journals, books, magazines and the internet.

Besides, the time used to obtain secondary data is almost the same compared to the collection of primary data. Disadvantage for the secondary data is that data obtained is not accurate and may be outdated compared to primary data. The study utilized secondary sources including the United Nations as well as the Ghana Armed Forces official documents. Additionally, journal articles, books, news reports, newspaper articles, video documentaries and commentaries were considered. All these were used in addition to the general literature on the GAF. The UN official website, as well as the Ghana Armed Forces official website where relevant data pertinent to the topic could be obtained were also sought. The soft copies of relevant books and articles were downloaded whilst the hard copy materials were obtained through libraries of institutions such as the University of Ghana (UG), Ghana Armed Forces Command and Staff College (GAFSCS), the Legon Center for International Affairs and Diplomacy (LECIAD) and the Kofi Annan International Peacekeeping Training Centre (KAIPTC), whilst others were purchased. The document content analysis approach was the basis for drawing conclusions from the secondary data in this study. Sampling is a process that uses samples selected for a certain population in a research project (Neuman \& Robson, 2014). It is important to use the sampling rather than the whole population elements to get an effective and efficient result for the research project. According to Sekaran \& Bougie (2010), the use of sampling helps to reduce the risks of error and other factors such as limited time, insufficient budget, and human resource factors. Therefore, the sampling design process includes the confirmation of target population, sampling technique, and sampling size. This process gives a clear direction for the research survey.

Bhattacherjee (2012) defines target population as the whole set of elements that are selected by the researcher for the investigate purpose. The target population has the specific and key characteristics required for the study. Notwithstanding several state security agencies in Ghana which carry out engineering project as part of their Cooperate Social Responsibilities (CSRs), the target population for this particular study will include workers, officials and personnel of the Ghana Armed Forces (GAF) since it is the study area of the work. However, expert views from some security experts was also considered.

There are two main types of sampling techniques for determining the sample size for carrying out a research work (Noor, 2008). These are probability and non-probability sampling techniques. Probability sampling is where elements of the population are known, which means that the researcher has the list of the population and all sampling elements have a chance to be selected. With non-probability sampling, the elements in a population are unknown. Thus, the probability of selection for each element is unknown. This study makes use of non-probability technique since the researcher could not have collected the full list of the target population elements. 
According to Sekaran and Bougie (2010), there are four types of the non-probability technique namely, convenience sampling, judgment sampling, quota sampling, and snowball sampling. Convenience sampling is the sampling where elements are selected because they are convenient to the researcher. Judgment sampling is the sampling method in which researchers select the elements based on their own judgment due to some specific characteristics. Moreover, quota sampling is where the researchers divide the target population into subgroups and select the elements following the proportion of population size. Snowball sampling is where the researcher may choose to select the sampling elements through the recommendation from the initial respondents and the initial respondents are selected by using the probability method (Noy, 2008).

This study utilized the convenience, purposive and snowball sampling methods. Convenience sampling is a non-probability sampling technique where participants or subjects included in a study are selected due to their convenience or proximity to the researcher (Cohen \& Arieli, 2011). This method is chosen for this study because, subjects/participants/persons to be interviewed were selected whilst on duty or at work. This is due to the busy schedules of some of the respondents as well as the difficulty in contacting them to provide responses that will be relevant for the data analysis. A purposive sampling according to Cohen \& Arieli (2011) involves intentionally selecting units of the sample population for a particular research based on the purpose of the study. This is because, the selected sample population share the same characteristics. Snowball sampling is where the researcher chooses to select the sampling elements through the recommendation from the initial respondents and the initial respondents are selected by using the probability method (Noy, 2008).

Sampling size for a research project is important because it may affect the result of a study. A proper sampling design should follow an effective samples size to get an accurate result from the research project. According to Sekaran and Bougie (2010), the too large number of sampling size or too small number of sampling size is not suitable to generate a good result. Therefore, the sample size for this study involved thirty (30) respondents comprising Junior and Senior staff of the GAF, with special focus on personnel of Ghana Army Engineer Corps. Selections of respondents for experts was done purposely to provide relevant data for the study.

\section{Discussions}

The research sought out to assess the quality performance of engineering projects: a case of the Ghana Armed Forces (GAF). The main objective of the study was to assess the quality performance among engineering projects of the GAF, with specific reference to the Ghana Army Corps of Engineers. The study would focus on the following specific objectives, assess some of the engineering projects of the GAF, examine the quality performance of GAF projects, with specific reference to the Ghana Army Corps of Engineers and ascertain the challenges to the quality of GAF projects undertaken by the Ghana Army Corps of Engineers. Data collection was done through questionnaires and interviews. Out of the 32 questionnaires distributed, 30 were retrieved. A total of 3 interviews were run. For the purposes of this research, an invitation letter was issued to the GAF officials to seek their consent. A pilot study was done using the questionnaire and an interview guide. The feedback from the pilot studies fed into the final structure of the study instruments, to ensure the expected data required for this research was obtained for analysis. 
The outcomes of the study were summarized as follows-general information, overview of engineering projects by Ghana Armed Forces and TQM deployment, challenges to implementing TQM in GAF engineering projects and interview outcomes. The analysis demonstrated that 16 approximately 53 per cent of the respondents were officers. 11 of the respondents were classified as 'order rank' and 3 respondents, 10 percent of the 30 were civilian. $24(80.00 \%)$ of the respondents were males and the rest $6(20.00 \%)$ were female respondents. It indicated that most of the workers at Ghana Armed Forces are possibly males. 5 (16.67\%) of the respondents were holding below Diploma certificate or a qualification equivalent to that. 2 of the respondents amounting to $6.67 \%$ of the respondents had Diploma qualification. 16 of the 30 respondents (53.33\%) held a first degree. 7 of the GAF staff contacted have a master's degree certificate. It showed highly educated majority of the Ghana Armed Forces. 3 of them $(10.00 \%)$ have been under the services of the Ghana Armed Forces for between a year and 5. Majority of them, 13 respondents (43.33\%) of the respondents are serving the Ghana Armed Forces for more than 5 years but not above 10 years. A total of 3 respondents amounting to $10 \%$ of them, by length of service should be more experienced working at GAF for about 11 to 15 years. 11 respondents have been the most experienced working with GAF. This is because they have been working with the Ghana Armed Forces for 15 years or more.

A lot of construction projects had been carried out by the Ghana Armed Forces. These projects have been grouped into two; namely, horizontal and vertical constructions. The horizontal constructions undertaken by the GAF included road projects, bridges and dredging of water basins. It has to do with all projects lying on the land, floor or ground. Per the reports as well, the vertical constructions were all those that had been elevations or heights. These included school buildings, army quarters and all other projects erected by the GAF.

Total Quality Management is a philosophy that is well understood by GAF staff according to the data gathered from the field. Figure 1, the pie chart shows that a whopping 26 respondents out of the 30 said they know about the term. In the process of quality management and techniques involved, Inspection and Quality assurance were mentioned to be the most tools used-13 respondents assented to each of them. Total Quality Management followed as another technique used by GAF. The data gathered and scrutinized have it that $83 \%$ ( 25 respondents) believed engineering projects undertook by GAF under the auspices of Quality Management, put the customer (the beneficiaries) at the center of the plans. Majority, 16 GAF staff demonstrated Total Quality Management has been successfully deployed by GAF in engineering projects.

\section{A. Challenges to Implementing TQM in GAF Engineering Projects}

The challenges were classified under management, finance, education, governance, technical and human attitude. Inadequate support and commitment were the major issue in management. Inadequate incentives and motivation represented the greatest challenge under finance. With education, inadequate technical skills came top. Bureaucracy was the major issue throughout; it was top under governance and rated highest among all the challenges to implementing Total Quality Management by GAF. Measurement strategies was the highest canker in the technical aspect of GAF. Transparency represent a major challenge considering the human attitude of GAF staff. 


\section{B. Outcomes of interview}

2 out of the 3 respondents said quality management was successfully implemented by GAF in engineering projects. If that is the case it represented something dissimilar to the research undertook in Yemen. 'The Effect of Total Quality Management on Construction Project Performance Case Study: Construction Firms in Yemen', was the title of the research carried out by Saeed and Hasan (2012). To an avail, Yemenites had very little adherence to total quality management practices or principles. All 3 of them identified government as the major customer of engineering projects.

GAF maintains and implements total quality management in projects by continuous improvement in services provided and quality leadership, monitoring and strict supervision of its projects and, periodically inspecting the projects to ensure that, the approved designs are executed. Quality management by GAF were observed by interviewees to be not so very effective as similar to in Pakistan, it was found out that there is inadequate knowledge on total quality management in the construction industry, thus total quality management techniques are not strictly adhered to in contracts (Attaullah, Ali, Mehmood \& Iqbal, 2014), on the same basis, two of them said not all engineering projects have met total quality standards. The 3 interviews proclaimed that standard could be improved through broad consultation with end users since the end user determines the level of quality of a project, providing refresher training to its artisans, supervisors and managers to be abreast with modern technology and, the GAF must fully implement TQM and ensure continues improvement on all its projects. Similarly, Bora and Alamsyah (2018) sought to explain and address on the issues; which were while projects were being undertaken, management had to expend another time tutoring how effective practices should be done to ensure that all quality features were adhered to. The other was noticing that there was gross decline in capacity of employees or being handed a new project where labour needed to be reskilled to meet job challenges.

\section{Conclusion}

The study sought out to assess the quality performance of engineering projects: a case of the Ghana Armed Forces (GAF). The main objective of the study was to assess the quality performance among engineering projects of the GAF. The research focused on the following specific objectives, assessed some of the engineering projects of the GAF, examined the quality performance of GAF projects, with specific reference to the Ghana Army Corps of Engineers and ascertain the challenges to the quality of GAF projects undertaken by the Ghana Army Corps of Engineers.

The research concluded eventually that there were a lot of engineering projects undertook buy GAF, which were grouped into horizontal and vertical constructions. One conclusion was also that not all GAF's engineering projects were of the required standards and quality. Another conclusion was also that though there were a lot of challenges to Total Quality Management in engineering projects by GAF, bureaucracy and poor measurement strategies were the most pronounced. Upon the findings and summaries of the research, the following recommendations were stipulated. GAF should specialize in an area of engineering projects to ensure quality is improved- they were doing a lot of vertical and horizontal projects. There should be continuous education or 
retraining among Ghana Armed Forces (GAF) to ensure level of standards and quality in projects are increased. Unnecessarily long chain of commands at Ghana Armed Forces (GAF) should be revised to ensure efficient decision making on projects.

Measurement strategies of ongoing or finished projects should be relooked at and revised to meet global or scientific standards or quality. Philip Crosby says if you spend money on quality, it is money that is well spent. He based his argument on four absolutes of quality management; defining quality as adherence to requirements, preventive measure is the best way to ensure quality, error is the performance standard for quality and quality is measured by the price of nonconformity (Boughzala, 2014).

\section{References}

Abd-Elwahed, M. S., \& El-Baz, M. A. (2018). Impact of implementation of total quality management: An assessment of the Saudi Industry. South African Journal of Industrial Engineering, 29(1), 97-107.

Addae, S. K. (2005). A Short History of Ghana Armed Forces. Ministry of Defence of Ghana Armed Forces. Alomi, Y. A., Alghamdi, S. J., \& Alattyh, R. A. (2015). Strategic Plan of General Administration of Pharmaceutical Care at Ministry of Health in Saudi Arabia 2012-2022. J Pharm Pharm Sci, 1(3), 1-8.

Aubyn, F., \& Aning, K. (2015). Peacekeeping contributor profile: Ghana. Accessed November, 23, 2015.

Black, S. A., \& Copsey, J. A. (2014). Does Deming's "System of Profound Knowledge" Apply to Leaders of Biodiversity Conservation? Open Journal of Leadership, 3(02), 53.

Boughzala, I., De Vreede, T., Nguyen, C., \& De Vreede, G. J. (2014, January). Towards a maturity model for the assessment of ideation in crowdsourcing projects. In 2014 47th Hawaii International Conference on System Sciences (pp. 483-490). IEEE.

Dellinger, A. B., \& Leech, N. L. (2007). Toward a unified validation framework in mixed methods research. Journal of Mixed Methods Research, 1(4), 309-332.

Diplomacy, A. A. T. O. (2012). Ghana Armed Forces (Doctoral dissertation, University of Ghana).

Farooqui, R. U., Masood, R., \& Aziz, J. (2008). Assessing the Viability of Total Quality Management Implementation in Contracting Pakistani Construction industry. Const. in Developing Count., 482.

Finkler, S. A., Smith, D. L., \& Calabrese, T. D. (2018). Financial management for public, health, and not-for-profit organizations. CQ Press.

Gogate, P., Mukhopadhyaya, D., Mahadik, A., Naduvilath, T. J., Sane, S., Shinde, A., \& Holden, B. (2013). Spectacle compliance amongst rural secondary school children in Pune district, India. Indian journal of ophthalmology, 61(1), 8.

Instruction, A. F. (2015). Instruction 33-360. Publications and Forms Management, 1.

Kagiri, D., \& Wainaina, G. (2017). Time and Cost Overruns in Power Projects in Kenya: A Case Study of Kenya Electricity Generating Company Limited. Orsea Journal, 3(2).

Khodeir, L. M., \& Mohamed, A. H. M. (2015). Identifying the latest risk probabilities affecting construction projects in Egypt according to political and economic variables. From January 2011 to January 2013. HBRC journal, 11(1), 129-135. 
Khodeir, L. M., \& Mohamed, A. H. M. (2015). Identifying the latest risk probabilities affecting construction projects in Egypt according to political and economic variables. From January 2011 to January 2013. HBRC journal, 11(1), 129-135.

Kunda, G. (2009). Engineering culture: Control and commitment in a high-tech corporation. Temple University Press.

Lichtenstein, S., Badu, E., Owusu-Manu, D. G., John Edwards, D., \& D. Holt, G. (2013). Corporate social responsibility architecture and project alignments: A study of the Ghanaian construction industry. Journal of Engineering, Design and Technology, 11(3), 334-353. Lyapunov, A. (2014). AP Heritage.

Mabbett, T. (2018). Perceptions of tertiary education service quality: an investigation into providing quality service encounters for international students: a thesis presented in partial fulfilment of the requirements for the degree of Masters of Quality Systems at Massey University, Manawatū, New Zealand (Doctoral dissertation, Massey University).

Mane, P. P., \& Patil, J. R. (2015). Quality management system at construction project: A questionnaire survey. Int. Journal of Engineering Research and Applications, 5(3), 126- 130.

Neath, S., Hulse, R., \& Codd, A. (2014). Building information modelling in practice: transforming

Gatwick airport, UK. Proceedings of the Institution of Civil Engineers, 167(2), 81. Neyestani, B., \& Juanzon, J. B. P. (2017). ISO 9001 Standard and Organization's Performance: A Literature Review. International Journal of Advanced Multidisciplinary Research, 4(2), 6-13.

Raja, K. S., \& Mubeena, M. Assessment of Total Quality Management in Construction Industry.

Sadikoglu, E., \& Olcay, H. (2014). The effects of total quality management practices on performance and the reasons of and the barriers to TQM practices in Turkey. Advances in Decision Sciences, 2014.

Saeed, N. M. N., \& Hasan, A. S. (2012). The effect of total quality management on construction project performance. Journal of Science and Technology, 17.

Sano, J. C. (2018). Urban Environmental Infrastructure In Kigali City Rwanda. Challenges and opportunities for modernised decentralised sanitation systems in poor neighbourhoods. Wageningen University, Wageningen.

Scientific Committee. Poster Presentation Abstracts. Journal of Cancer \& Allied Specialties, 3(4). Shields, P. M., \& Rangarajan, N. (2013). A playbook for research methods: Integrating conceptual frameworks and project management. New Forums Press.

Shuaib, M. R. (2018). Determinant of Imports of Manufactured Goods in Nigeria (1980- 2016) (Doctoral dissertation, Kwara State University (Nigeria)).

Wei, H. H., Liu, M., Skibniewski, M. J., \& Balali, V. (2016). Prioritizing sustainable transport projects through multicriteria group decision making: Case study of Tianjin Binhai New Area, China. Journal of Management in Engineering, 32(5), 04016010. 